\title{
A systematic review of observational studies evaluating costs of adverse drug reactions
}

This article was published in the following Dove Press journal:

ClinicoEconomics and Outcomes Research

24 August 2016

Number of times this article has been viewed

Francisco Batel Marques ${ }^{1,2}$

Ana Penedones 1,2

Diogo Mendes ${ }^{1,2}$

Carlos Alves ${ }^{1,2}$

'CHAD - Centre for Health Technology Assessment and Drug Research, AIBILI - Association for Innovation and Biomedical Research on Light and Image, ${ }^{2}$ School of Pharmacy, University of Coimbra, Coimbra, Portugal
Correspondence: Francisco Batel Marques AIBILI - Association for Innovation and Biomedical Research on Light and Image, Azinhaga de Santa Comba, 3000-548,

Coimbra, Portugal

Tel +35I 239480100

Fax +35I 239480 II7

Email batelmarques@gmail.com
Introduction: The growing evidence of the increased frequency and severity of adverse drug events (ADEs), besides the negative impact on patient's health status, indicates that costs due to ADEs may be steadily rising. Observational studies are an important tool in pharmacovigilance. Despite these studies being more susceptible to bias than experimental designs, they are more competent in assessing ADEs and their associated costs.

Objective: To identify and characterize the best available evidence on ADE-associated costs. Methods: MEDLINE, Cochrane Library, and Embase were searched from 1995 to 2015 . Observational studies were included. The methodological quality of selected studies was assessed by Cochrane Collaboration tool for experimental and observational studies. Studies were classified according to the setting analyzed in "ambulatory", "hospital", or both. Costs were classified as "direct" and "indirect". Data were analyzed using descriptive statistics. The total incremental cost per patient with ADE was estimated.

Results: Twenty-nine (94\%) longitudinal observational studies and two (7\%) cross-sectional studies were included. Twenty-three (74\%) studies were assessed with the highest methodological quality score. The studies were mainly conducted in the US (61\%). Twenty (65\%) studies evaluated any therapeutic group. Twenty (65\%) studies estimated costs of ADEs leading to or prolonging hospitalization. The "direct costs" were evaluated in all studies, whereas only two (7\%) also estimated the "indirect costs". The "direct costs" in ambulatory ranged from $€ 702.21$ to $€ 40,273.08$, and the in hospital from $€ 943.40$ to $€ 7,192.36$.

Discussion: Methodological heterogeneities were identified among the included studies, such as design, type of ADEs, suspected drugs, and type and structure of costs. Despite such discrepancies, the financial burden associated with ADE costs was found to be high. In the light of the present findings, validated methods to measure ADE-associated costs need future research efforts. Keywords: drug costs, health care costs, drug-related side effects and adverse reactions, review

\section{Introduction}

In 1999, Wolfe et al described nonsteroidal anti-inflammatory drug toxicity as a leading cause of mortality in the US, ahead of multiple myeloma, asthma, cervical cancer, and Hodgkin's disease, and similar to the acquired immunodeficiency syndrome. ${ }^{1}$ A marked increase in reported deaths and serious injuries associated with drug therapy in the US highlighted the importance of this problem as a public health issue, providing strong evidence that postmarketing drug surveillance plays an increasingly important and essential role in the fields of clinical risk management and drug regulation, mainly in terms of assessing benefit/risk ratios, health economics, and public health. ${ }^{2}$ 
The growing evidence of the increased frequency and severity of adverse drug events (ADEs), besides the negative impact on patient's health status, indicates that costs due to ADEs may be steadily rising. The epidemiology of drug iatrogenesis across Europe has been identified as an area needing more study, particularly in the ambulatory health care environment, due to the scarcity of available data. ${ }^{3}$ Furthermore, in some European countries, underreporting of ADEs has been identified as a pharmacovigilance shortcoming, anticipating that the economic burden of adverse effects of drugs may be underestimated. ${ }^{3}$

The costs of ADEs are a key component of the cost structure in health economic analysis and pharmacoeconomic studies. However, both data sources for ADE costs identification and methods of costs measurement vary among the different available studies. ${ }^{4}$ Moreover, previous reviews pointed out a large methodological heterogeneity in measuring drug-induced morbidity.

Experimental and observational studies data can be used to estimate costs of ADEs. However, experimental studies are mainly designed to evaluate the efficacy of an intervention and the conclusions of ADEs and their related costs are difficult to draw due to their methodological limitations, such as length of exposure and the homogeneity of included patients. Observational studies, despite being more susceptible to bias, are more competent in assessing ADEs in clinical practice and allocating their costs than experimental studies. ${ }^{5,6}$

In this light, a systematic review of observational studies was carried out aiming at identifying and characterizing the best available evidence on ADE-associated costs.

\section{Methods}

This systematic review followed the recommendations of the Preferred Reporting Items for Systematic Reviews and Meta-Analyses statement. ${ }^{7}$

\section{Literature search}

A systematic search was conducted from 1995 to 2015 in MEDLINE, Cochrane Library, and Embase to identify studies describing the costs of ADEs. Search terms related with costs of ADEs were identified consulting the Medical Subject Headings ${ }^{8}$ and Emtree terms. ${ }^{9}$ Only literature published in English language in the last 20 years was considered for inclusion in this analysis. The search strategy is listed in Tables S1 and S2.

\section{Study selection and quality assessment}

Two researchers independently screened by hand the titles and abstracts and selected full articles for inclusion.
In case of disagreement, the opinion of a third investigator was sought.

Longitudinal and cross-sectional observational studies were eligible for inclusion if they had been conducted in the US or European countries, and reported on average costs of treating ADEs or reported enough data to perform such estimations.

For the purposes of this study, an ADE was defined according to the World Health Organization definition as "any untoward medical occurrence in a patient or clinical trial subject administered a medicinal product". ${ }^{10}$

The quality of the retrieved studies was assessed using the checklist proposed by the Cochrane Collaboration for assessment of nonrandomized studies. ${ }^{11}$

\section{Data extraction}

Data on study design, study duration, data source, country, and setting of cost analysis were extracted in order to characterize the study design of the included studies. Additionally, data on study size, eligible patients, type of ADE(s) evaluated, $\operatorname{drug}(\mathrm{s})$ considered, type of cost analysis, cost component(s) assessed, and the estimated cost(s) were retrieved.

Studies were classified in two categories according to the type of costs analyzed: "ambulatory" if the costs estimated were of $\operatorname{ADE}(\mathrm{s})$ leading to hospitalization occurring in nonhospitalized patients, and in "hospital" if the costs estimated were of $\operatorname{ADE}(s)$ occurring during hospitalization.

\section{Data analysis and presentation}

Data were analyzed using descriptive statistics. The unit of measure of costs considered was the average incremental cost per patient with an ADE compared to a patient without an ADE. Some assumptions and conversions had to be made when studies reported other outcomes. As an example, if a study reported the incremental cost of treating a patient with an ADE over a month, that cost was converted to the total cost of treating a patient with an ADE irrespective of the time frame by considering the total number of patients analyzed and the average time of follow-up. The incremental cost was calculated as ([consumer price index in 2014/ consumer price index in the year of analysis]* incremental cost in the year of the study). All costs were presented in euros $(€)$. The website of The Organisation for Economic Co-operation and Development was screened to identify currency exchange rates and consumer price indices per country. ${ }^{12}$ Currency exchange rates established by the end of the year 2014 were used to convert other currencies to euros $(€)$. Consumer price indices were used to adjust for the effect of costs' inflation estimated in studies conducted 
years ago to predicted costs by the year 2014. Data analyses were performed using Microsoft Excel 2010 (Microsoft Corporation, Redmond, WA, USA).

\section{Results}

The search yielded a total of 625 potentially relevant references. After excluding for duplicates, 458 abstracts were reviewed and screened for eligibility. Based on inclusion criteria, 90 references were selected for full-text further evaluation. A final sample of 31 studies was eligible for inclusion. The selection of references is shown in Figure 1.

\section{Characteristics of the selected studies}

The 31 studies selected for further analyses included 22 cohort studies $(71.0 \%)$, seven case-control studies $(22.6 \%)$, and two studies based on pharmacovigilance databases of spontaneously reported ADEs (6.4\%). Table 1 describes the main characteristics of the studies. Seventeen cohort studies (77.3\%) and six case-control studies $(85.7 \%)$ were assessed as having a low risk of bias (Table S3).

The mean duration of the included studies was 19 months (53 days to 18 years). The studies were mainly conducted in the US $(\mathrm{n}=19 ; 61.3 \%)$.
Thirteen studies (41.9\%) estimated the costs of ADEs occurring in the outpatient setting, ten studies (32.3\%) estimated the costs both in "ambulatory" and "hospital" settings, and eight studies (25.8\%) assessed the costs occurring during hospitalization.

Twenty studies (64.5\%) did not evaluate any therapeutic group in particular. Among the studies which analyzed a specific therapeutic group, the costs of ADEs caused by medicines used for cancer treatment were the more commonly evaluated $(\mathrm{n}=6 ; 19.4 \%)$.

Most part of the studies assessed all ADEs resulting from the utilization of a drug. They not assessed a specific ADE (eg, skin toxicity related with erlotinib). Regarding studies assessing an ADE of a particular type, cutaneous events were the most evaluated $(\mathrm{n}=4 ; 12.9 \%)$.

Two studies (6.5\%) evaluated the costs of ADEs in pediatric population and three studies $(9.7 \%)$ studied specifically the geriatric population. ${ }^{13-17}$

\section{Cost analysis}

Table 2 describes the costs analysis and the main results of the included studies.

A total of 29 (93.5\%) studies evaluated "direct health care costs", and two studies (6.5\%) issued both "direct and

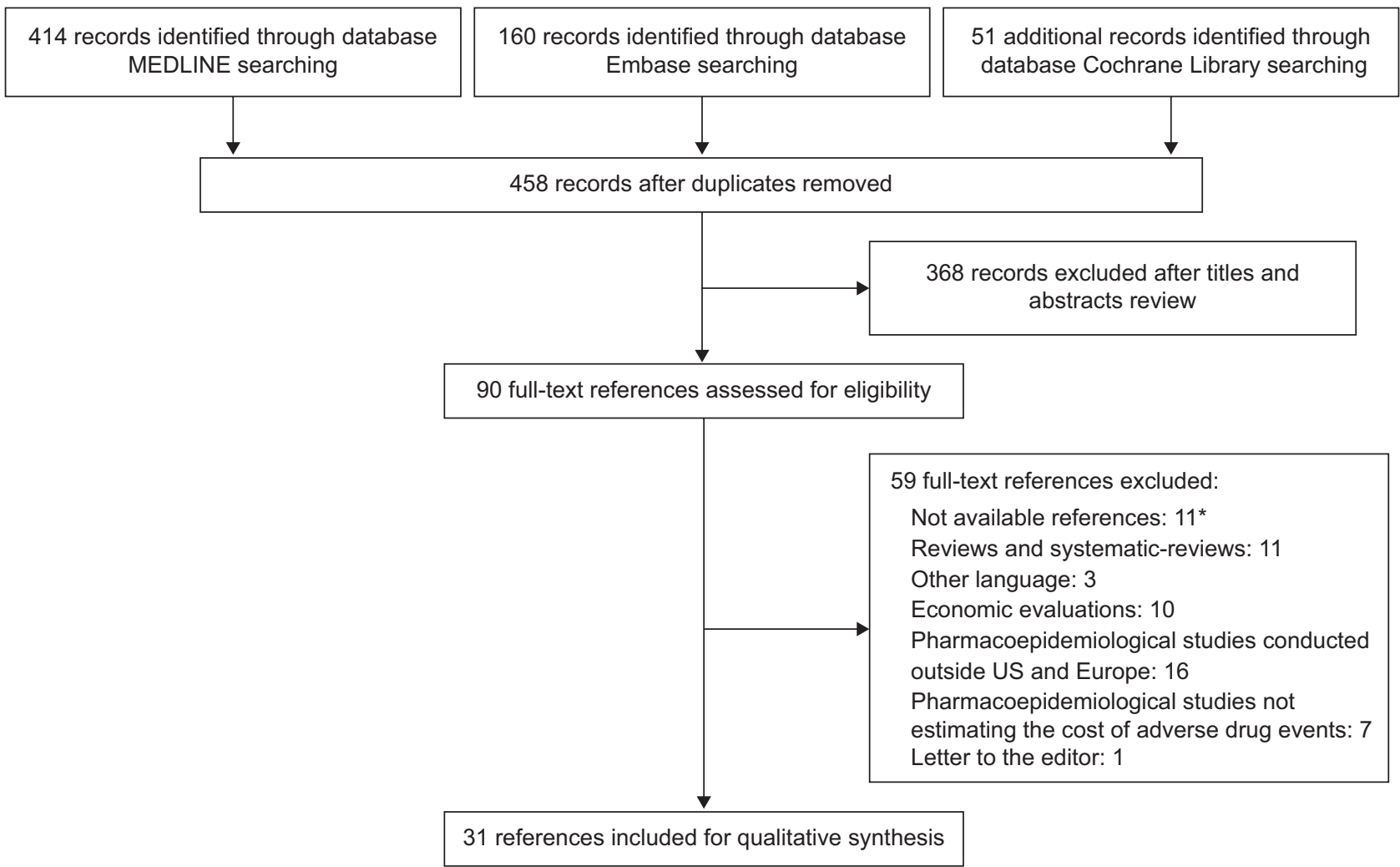

Figure I Flow diagram of literature search.

Notes: *The references are not available on the electronic databases searched. The publications' authors did not reply to our request to access the publication's full-text. 


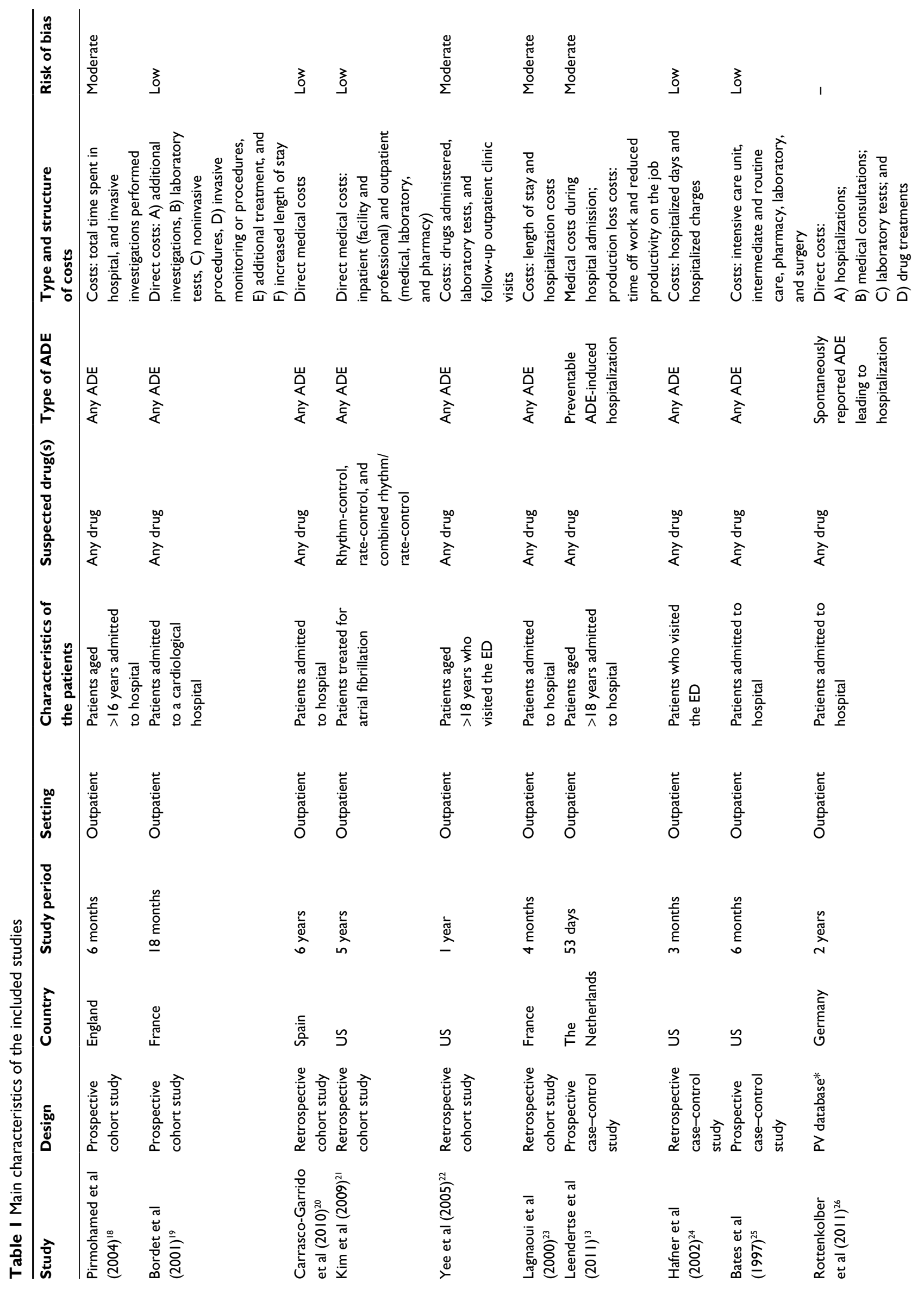



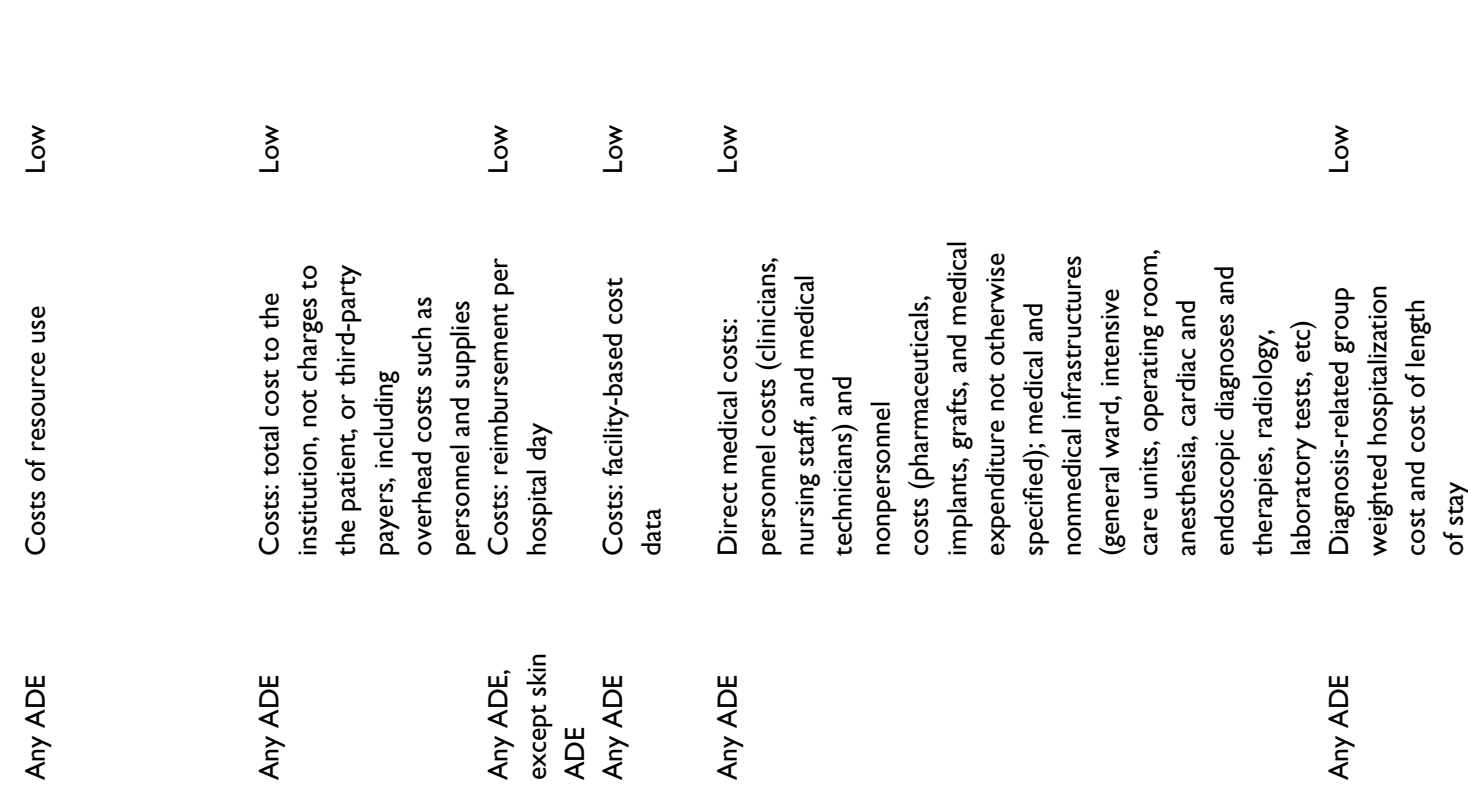

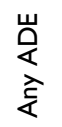

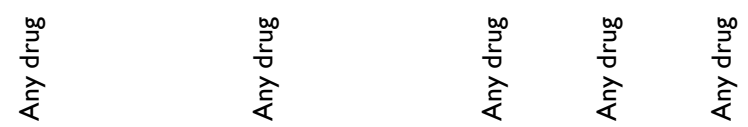

章

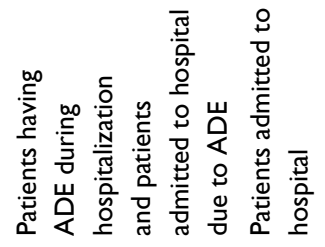

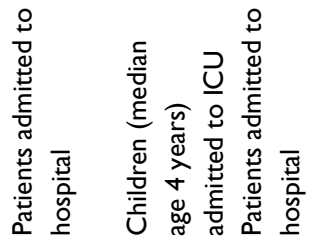
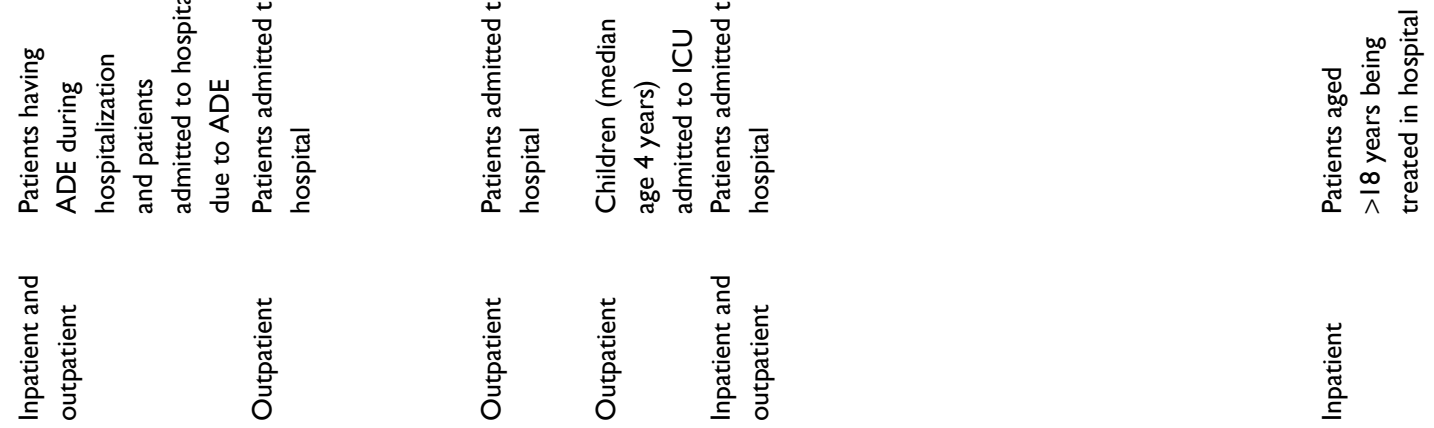

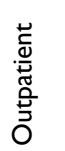

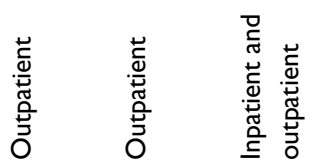
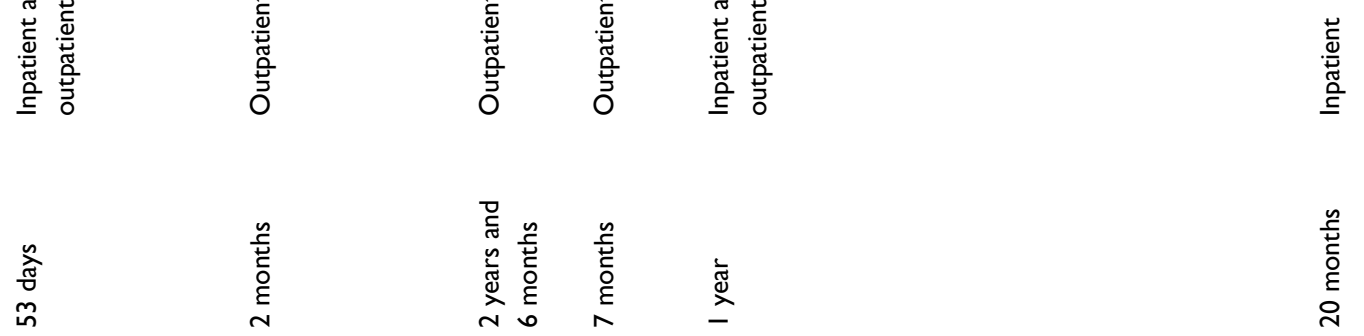

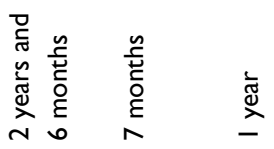
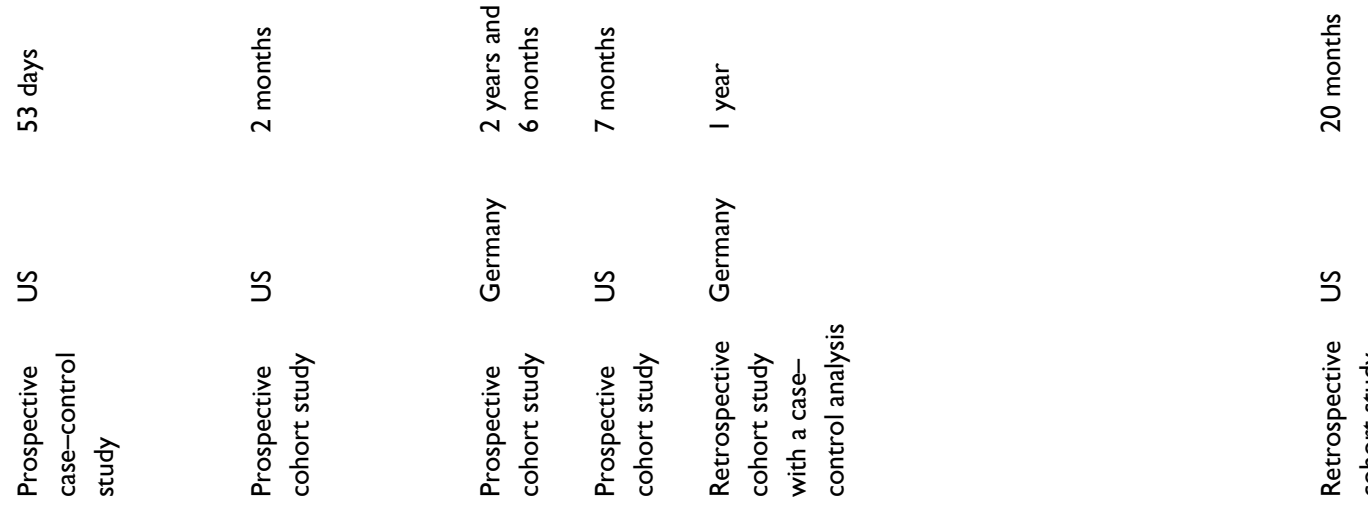

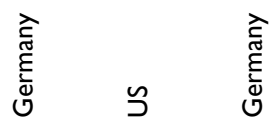

ร
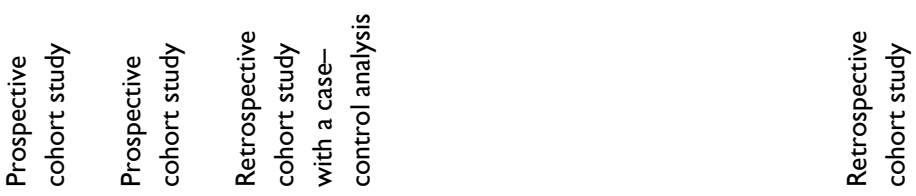

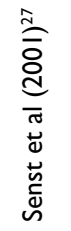
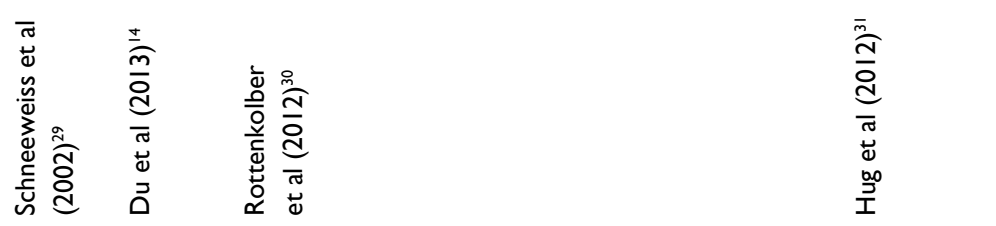


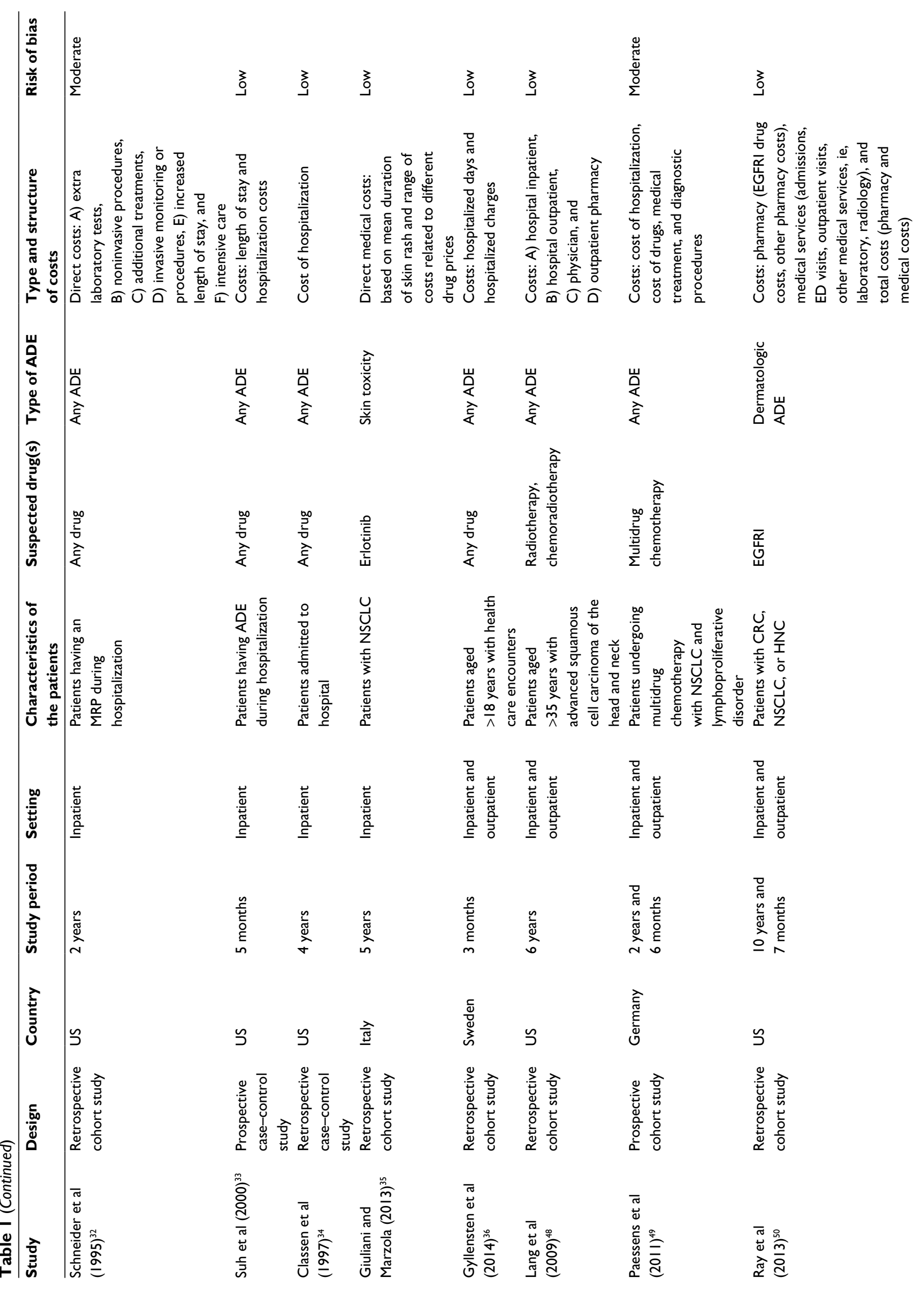


$\begin{array}{llllll}3 & 3 & 3 & 3 & 3 & 3\end{array}$

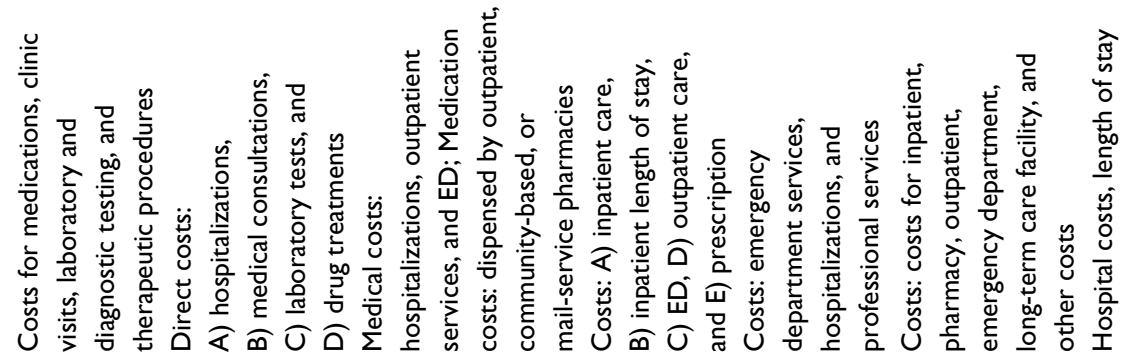

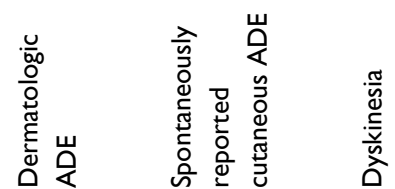

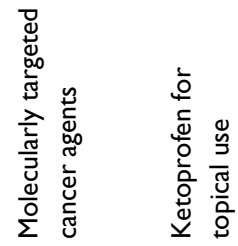

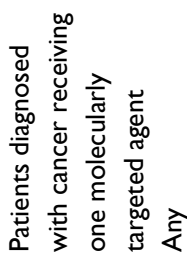

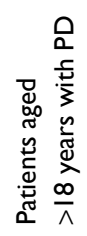
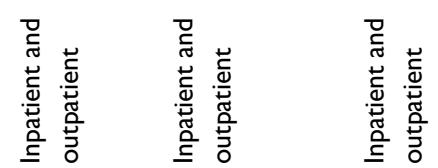

กั

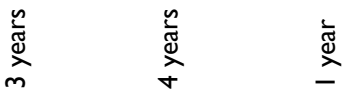

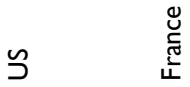

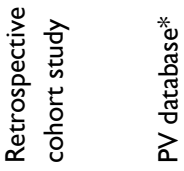

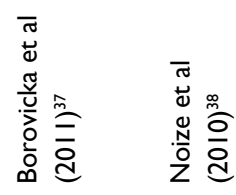

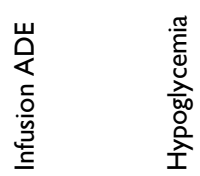

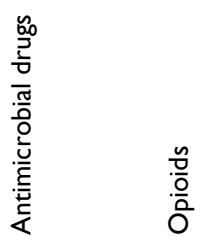

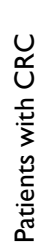

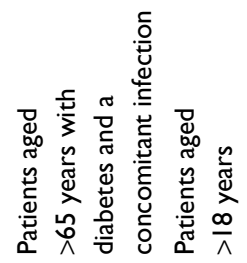

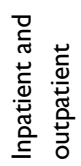

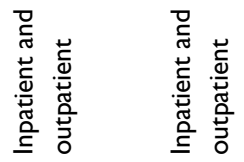

舟

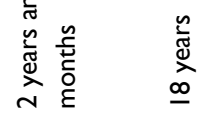
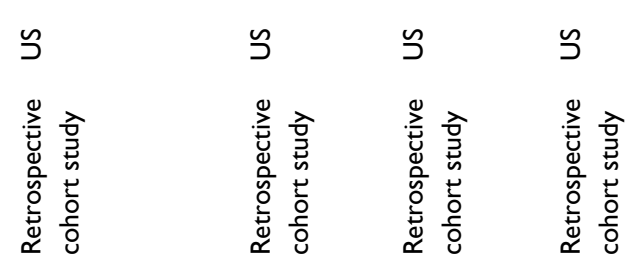

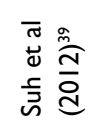

$\frac{.0}{4}$

$\frac{0}{200}$

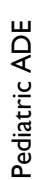

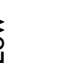

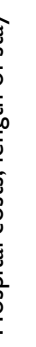

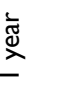

$\stackrel{\frac{1}{d}}{\grave{2}}$
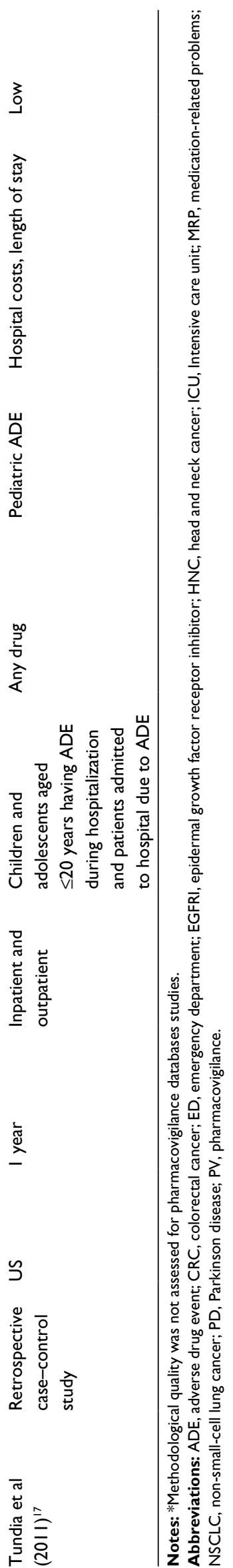

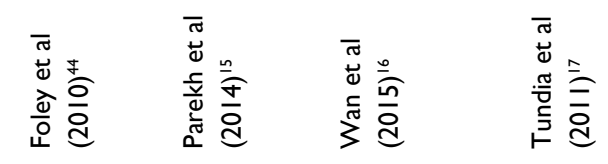

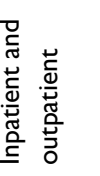

s

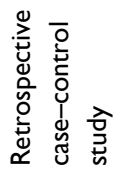


indirect health care costs". Costs related to facility expenses and treatment were the type of direct health care costs most assessed ( $\mathrm{n}=18 ; 58 \% ; \mathrm{n}=17 ; 55 \%$, respectively).

The costs of ADEs related to any drug occurring in nonhospitalized patients has been estimated from $€ 702.21$ to $€ 40,273.08 .^{13,14,18-29}$ A study investigated the costs of ADEs related to rhythm-control, rate-control, and combined rhythm-/rate-control medication; the costs per patient with an ADE were estimated to be $€ 2,737.46 .{ }^{21}$ Leendertse et al assessed the costs of ADEs in geriatric population whereas $\mathrm{Du}$ et al estimated the costs of ADEs in pediatric population. ${ }^{13,14}$ The incremental total cost per patient with an ADE was estimated as $€ 6,527.37$ and $€ 40,273.08$, respectively. ${ }^{13,14}$

The costs of ADEs that occurred during hospitalization varied from $€ 943.40$ to $€ 5,972.74 .{ }^{30-35} \mathrm{Hug}$ et al compared the costs of any ADE, serious ADE, and life-threatening ADE; an increase in costs related to the seriousness of the ADEs was found (€3,030.79; €3,234.61; €7,192.36, respectively). ${ }^{31}$ Another study estimated the costs of skin ADEs related to erlotinib as $€ 1,105.54$. $^{35}$

Several studies assessed the costs of ADEs both in hospitalized and nonhospitalized patients (Table 2). The costs of skin ADEs related to antineoplastic agents were estimated from $€ 1,592.89$ to $€ 15,037.97 .{ }^{36,37}$ A study evaluated the costs of nonserious and serious skin ADEs according to spontaneous reports; the incremental total cost per patient was estimated as $€ 373.33$ and $€ 3,383.56$, respectively. ${ }^{38}$ Suh et al estimated the costs of levodopa-induced dyskinesia as $€ 4,617.65 .{ }^{39}$ Parekh et al assessed the costs of hypoglycemia in patients aged $>65$ years as $€ 25.41$ per episode. ${ }^{15}$ Another study investigated the costs of ADEs in pediatric population as $€ 3,242.59 .{ }^{17}$

Few studies $(n=2 ; 6.5 \%)$ assessed indirect health care costs of ADEs (Table 3). Leendertse et al estimated the indirect health care costs of any ADE leading to hospitalization as $€ 1,982.41$ for patients younger than 65 years and as $€ 0.00$ for patients aged 65 years or older, according to productivity costs including time off work and reduced productivity on the job. ${ }^{13}$ Another study evaluated the indirect health care costs of any ADE both in hospitalized and nonhospitalized patients as $€ 2,985.26$. $^{36}$

\section{Discussion}

A wide range of values representing both incremental and total costs was found in this study, which may be explained by the methodological differences between included studies.

Of a total of 31 studies (19 from North-America and 12 from Europe), observational longitudinal designs (cohort $[\mathrm{n}=22 ; 71 \%]$ and case-control $[\mathrm{n}=7 ; 23 \%])$ constituted the most frequent methodology observed (94\%).
As pointed out by the results of this study, the identification of ADE costs has been focused on hospital setting in two ways: as cause of hospitalization or hospitalization prolongation. Therefore, studies were grouped according to the settings from where data were collected: nonhospitalized patients with ADEs leading to hospitalization, hospitalized patients with ADEs during the hospitalization, and a third group of ADEs simultaneously from outpatients and inpatients. In this last group, a specific setting could not be well established. Several reviews also illustrated these results. ${ }^{4,40,41}$ The hospital setting was the privileged set for identification of ADEs and their costs. These data are easier to assess in administrative databases from hospitals while a complete description of each case was hard to obtain in ambulatory setting. ${ }^{41}$

Within the different above-established groups, several methodological heterogeneities were found. Some studies focused on the associations between any drug and any ADE, others on the association of one specific ADE, and several drugs or on the association between any ADE and one specific drug. The study of the association between one specific drug and one specific ADE was also found. Moreover, some studies only included serious ADEs, while others included serious and nonserious ADEs. In addition, some studies assessed ADEs treated in different hospital units, such as emergency departments and intensive care units, resulting in disparate values of ADE costs. For instance, in the study of Du et al, the incremental total cost per patient with ADE was estimated as $€ 40,273.08$, not only due to the specific population analyzed (pediatric) but also due to the setting analyzed (intensive care unit). ${ }^{14}$ Another source of heterogeneity was the diversity of the drugs evaluated in the studies, which may have contributed to the high costs variation. Most of the studies included in this systematic review did not focus in any particular therapeutic group of drugs. Among the studies evaluating specific therapeutic groups $(n=11)$, six were designed to estimate the costs associated with antineoplastic drugs. Of note, oncology was one of the therapeutic areas receiving more positive opinions for new active substances in recent years, both in Europe and the US. ${ }^{42,43}$ The study of the costs associated with treatments used in cancer is of upmost importance since these drugs are usually associated with a high burden of iatrogenics. ${ }^{44}$

Another source of heterogeneity was the metrics for cost evaluation in the different studies. Ninety percent of the studies solely identified direct costs, and different indexes were used for cost identification among studies. Information on indirect costs was difficult to access as it is associated with individual loss of productivity, and most studies evaluated different ADEs in a heterogeneous group of patients. ${ }^{44}$ 
Table 2 Incremental total direct health care cost per patient with ADE (€)

\begin{tabular}{|c|c|c|c|}
\hline Type of ADE & Reference & Drug & $\begin{array}{l}\text { Incremental total } \\
\text { cost per patient } \\
\text { with ADE }(€)\end{array}$ \\
\hline \multicolumn{4}{|c|}{ Nonhospitalized patients with ADEs leading to hospitalization } \\
\hline \multirow[t]{14}{*}{ Any ADE } & Pirmohamed et al $(2004)^{18}$ & Any drug & $3,682.82$ \\
\hline & Bordet et al $(2001)^{19}$ & Any drug & $5,187.50$ \\
\hline & Carrasco-Garrido et al $(2010)^{20}$ & Any drug & $4,910.12$ \\
\hline & Kim et al $(2009)^{21}$ & $\begin{array}{l}\text { Rhythm-control, rate-control, } \\
\text { and combined rhythm-/ } \\
\text { rate-control drug }\end{array}$ & $2,737.46$ \\
\hline & Yee et al $(2005)^{22}$ & Any drug & $3,593.60$ \\
\hline & Lagnaoui et al $(2000)^{23}$ & Any drug & $3,500.80$ \\
\hline & Leendertse et al $(201 \mathrm{I})^{* \neq \neq, 13}$ & Any drug & $5,891.65$ \\
\hline & Hafner et al $(2002)^{24}$ & Any drug & 702.21 \\
\hline & Bates et al $(1997)^{25}$ & Any drug & $3,209.82$ \\
\hline & Bates et al $(1997)^{\ddagger .25}$ & Any drug & $5,794.99$ \\
\hline & Rottenkolber et al $(201 \mathrm{I})^{26}$ & Any drug & $2,427.45$ \\
\hline & Rottenkolber et al $(2012)^{30}$ & Any drug & $2,140.49$ \\
\hline & Senst et al $(200 \mathrm{I})^{27}$ & Any drug & $7,318.14$ \\
\hline & Tafreshi et al $(1999)^{28}$ & Any drug & $\mathrm{I}, 303.40$ \\
\hline Any ADE, except skin ADE & Schneeweiss et al $(2002)^{29}$ & Any drug & 820.16 \\
\hline Any ADE in pediatric population & Du et al $(2013)^{14}$ & Any drug & $40,273.08$ \\
\hline Any ADE in geriatric population & Leendertse et al $(2011)^{13}$ & Any drug & $6,527.37$ \\
\hline \multicolumn{4}{|c|}{ Hospitalized patients with ADEs during the hospitalization } \\
\hline \multirow[t]{8}{*}{ Any ADE } & Rottenkolber et al $(2012)^{30}$ & Any drug & $1,049.69$ \\
\hline & Senst et al $(200 \mathrm{I})^{27}$ & Any drug & $2,366.77$ \\
\hline & Hug et al $(2012)^{\#, 31}$ & Any drug & $3,030.79$ \\
\hline & Hug et al $(2012)^{\mu, 31}$ & Any drug & $3,234.61$ \\
\hline & Hug et al $(2012)^{\S, 31}$ & Any drug & $7,192.36$ \\
\hline & Schneider et al $(1995)^{32}$ & Any drug & 943.40 \\
\hline & Suh et al $(2000)^{33}$ & Any drug & $5,972.74$ \\
\hline & Classen et al $(1997)^{34}$ & Any drug & $2,797.92$ \\
\hline Skin ADE & Giuliani and Marzola $(2013)^{35}$ & Erlotinib & $\mathrm{I}, 105.54$ \\
\hline \multicolumn{4}{|c|}{ Other (both hospitalized and nonhospitalized patients; spontaneous reports) } \\
\hline \multirow[t]{3}{*}{ Any ADE } & Gyllensten et al $(2014)^{36}$ & Any drug & 349.98 \\
\hline & Lang et al $(2009)^{48}$ & $\begin{array}{l}\text { Radiotherapy, } \\
\text { chemoradiotherapy }\end{array}$ & $8,509.24$ \\
\hline & Paessens et al $(201 \mathrm{I})^{49}$ & Multidrug chemotherapy & $4,213.97$ \\
\hline \multirow[t]{6}{*}{ Skin ADE } & Ray et al $(2013)^{50}$ & Panitumumab or cetuximab & $13,150.34$ \\
\hline & Ray et al $(2013)^{50}$ & Erlotinib or gefitinib & $14,860.76$ \\
\hline & Ray et al $(2013)^{50}$ & Cetuximab & $15,037.97$ \\
\hline & Borovicka et al $(20 \mathrm{ll})^{37}$ & $\begin{array}{l}\text { Molecularly targeted cancer } \\
\text { agents }\end{array}$ & $1,592.89$ \\
\hline & Noize et al $(2010)^{¥, 38}$ & Ketoprofen for topical use & 373.33 \\
\hline & Noize et al $(2010)^{\mu, 38}$ & Ketoprofen for topical use & $3,383.56$ \\
\hline Dyskinesia & Suh et al $(2012)^{39}$ & Levodopa & $4,617.65$ \\
\hline Infusion $A D E^{\beta}$ & Foley et al $(2010)^{\alpha, 44}$ & Cetuximab & $5,603.70$ \\
\hline Hypoglycemia & Parekh et al $(2014)^{12,15}$ & Antimicrobial drugs & $25.4 I$ \\
\hline Constipation & Wan et al $(2015)^{*, 16}$ & Opioids & $8,711.33$ \\
\hline Constipation & Wan et al $(2015)^{f, 16}$ & Opioids & $4,606.79$ \\
\hline Constipation & Wan et al $(2015)^{\mathrm{n}, 16}$ & Opioids & $\mathrm{I}, 240.17$ \\
\hline Any $A D E$ in pediatric population & Tundia et al $(20 \mathrm{II})^{17}$ & Any drug & $3,242.59$ \\
\hline
\end{tabular}

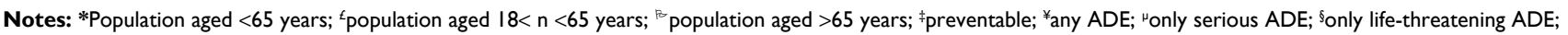
${ }^{\alpha}$ mean of both hospitalized and nonhospitalized patients; ${ }^{\beta}$ allergic and hypersensitivity ADE; apatients with long-term treatment with opioids.

Abbreviation: $A D E$, adverse drug event. 
Table 3 Incremental total indirect health care cost per patient with ADE (€)

\begin{tabular}{|c|c|c|c|}
\hline Type of ADE & Reference & Drug & $\begin{array}{l}\text { Incremental total cost per } \\
\text { patient with ADE }(€)\end{array}$ \\
\hline \multicolumn{4}{|c|}{ Nonhospitalized patients with ADEs leading to hospitalization } \\
\hline Any ADE & Leendertse et al $(201 \mathrm{I})^{*, 13}$ & Any drug & I,982.4I \\
\hline Any $A D E$ in geriatric population & Leendertse et al $(201 \mathrm{I})^{13}$ & Any drug & 0.00 \\
\hline \multicolumn{4}{|c|}{ Other (both hospitalized and nonhospitalized patients; spontaneous reports) } \\
\hline Any ADE & Gyllensten et al $(2014)^{36}$ & Any drug & $2,985.26$ \\
\hline
\end{tabular}

Note: *Population $<65$ years.

Abbreviation: $A D E$, adverse drug event.

The main strategy to identify ADEs and their related costs was the use of codes, such as International Classification of Diseases and Diagnosis-Related Group, and length of stay and their associated cost as an index measure. ${ }^{4,40,41}$ Analysis of spontaneous reports, review of medical charts, and computer searches are some examples of the different methods used to detect ADEs ${ }^{45}$ Each of these methodologies had different sensitivities to identify ADEs, leading to a possible underestimation of the real number of ADEs, therefore, reflecting the heterogeneity of the observed results. ${ }^{46}$

The calculation of costs was also subject of heterogeneity. Whereas some studies estimated the costs per episode of ADE per patient, such as in Parekh et al which assessed the costs of one episode of hypoglycemia, ${ }^{15}$ other studies estimated the costs of total ADEs per patient resulting from the total period of treatment, such as in oncology treatments. ${ }^{16}$

Data on the causality assessment between drug exposure and ADE were not available in any study. From a clinical and drug safety evaluation point of view, this is a relevant issue that should be included in future studies. However, when reflecting about ADE costs, investigators should carefully interpret studies as different causality methods can be applied, ${ }^{47}$ as well as distinct definitions of ADE. ${ }^{45}$ Such dissimilarities could lead to more heterogeneity. In addition, only for ADEs assessed as possible, probable and certain, the sensitivity analysis should be presented. ${ }^{45}$

The present findings are in line with the results from other studies. In fact, data on ADE costs not related with hospitalization are scarce, sometimes conflicting and mainly limited to direct costs. A more profound lack of knowledge on the subject is particularly seen in the ambulatory (outpatient) setting. ${ }^{4,40,41}$

This study has some limitations. The search was developed according to Medical Subject Headings and Emtree terms and only includes articles published in English, conducted in the US and Europe, and during the last 20 years. Methodological differences in the studies' designs can make the ADE cost impact assessment difficult. Such difficulties were encountered in this systematic review.
Despite the methodological discrepancies found between the studies included in this work, the burden of ADE costs is high, anticipating that the study of this issue deserves particular attention and further research efforts.

\section{Disclosure}

The authors report no conflicts of interest in this work.

\section{References}

1. Wolfe MM, Lichtenstein DR, Singh G. Gastrointestinal toxicity of nonsteroidal antiinflammatory drugs. $N$ Engl J Med. 1999;340(24):1888-1899.

2. Lazarou J, Pomeranz BH, Corey PN. Incidence of adverse drug reactions in hospitalized patients: a meta-analysis of prospective studies. JAMA. 1998;279(15):1200-1205.

3. Bouvy JC, De Bruin ML, Koopmanschap MA. Epidemiology of adverse drug reactions in Europe: a review of recent observational studies. Drug Saf. 2015;38(5):437-453.

4. Gautier S, Bachelet H, Bordet R, Caron J. The cost of adverse drug reactions. Expert Opin Pharmacother. 2003;4(3):319-326.

5. European network for Health Technology Assessment. Endpoints used in relative effectiveness assessment of pharmaceuticals - safety. EUnetHTA JA1 WP5 Methodology Guidelines, 2013. Available from: http://5026.fedimbo.belgium.be/sites/5026.fedimbo.belgium.be/files/ Safety.pdf. Accessed February 25, 2016.

6. Strom BL. Study designs available for pharmacoepidemiology studies. In: Strom BL, Kimmel SE, editors. Textbook of Pharmacoepidemiology. West Sussex: John Wiley \& Sons, Ltd; 2006:13-24.

7. Moher D, Liberati A, Tetzlaff J, Altman DG: PRISMA Group. Preferred reporting items for systematic reviews and meta-analyses: the PRISMA statement. Ann Intern Med. 2009;151(4):264-269.

8. U.S. National Library of Medicine. Medical Subject Headings. Available from: https://www.nlm.nih.gov/mesh/MBrowser.html. Accessed February 4, 2016.

9. Embase ${ }^{\circledR}$. Available from: https://www.elsevier.com/solutions/embasebiomedical-research. Accessed July 18, 2016.

10. Directive 2001/20/ec of the European parliament and of the council. Available from: http://ec.europa.eu/health/files/eudralex/vol-1/ dir_2001_20/dir_2001_20_en.pdf. Accessed February 4, 2016.

11. Cochrane Bias Methods Group. A Cochrane Risk of Bias Assessment Tool: for Non-Randomized Studies of Interventions (ACROBAT-NRSI). Available from: https://sites.google.com/site/riskofbiastool/. Accessed February 4, 2016.

12. The Organisation for Economic Co-operation and Development (OECD). Available from: www.oecd.org/. Accessed February 11, 2016.

13. Leendertse AJ, Van Den Bemt PM, Poolman JB, Stoker LJ, Egberts AC, Postma MJ. Preventable hospital admissions related to medication (HARM): cost analysis of the HARM study. Value Health. 2011;14(1): $34-40$.

14. Du W, Tutag Lehr V, Caverly M, Kelm L, Reeves J, Lieh-Lai M. Incidence and costs of adverse drug reactions in a tertiary care pediatric intensive care unit. J Clin Pharmacol. 2013;53(5):567-573. 
15. Parekh TM, Raji M, Lin YL, Tan A, Kuo YF, Goodwin JS. Hypoglycemia after antimicrobial drug prescription for older patients using sulfonylureas. JAMA Intern Med. 2014;174(10):1605-1612.

16. Wan Y, Corman S, Gao X, Liu S, Patel H, Mody R. Economic burden of opioid-induced constipation among long-term opioid users with noncancer pain. Am Health Drug Benefits. 2015;8(2):93-102.

17. Tundia NL, Heaton PC, Kelton CM. The national burden of E-codeidentified adverse drug events among hospitalized children using a national discharge database. Pharmacoepidemiol Drug Saf. 2011;20(8): 866-878.

18. Pirmohamed M, James S, Meakin S, et al. Adverse drug reactions as cause of admission to hospital: prospective analysis of 18820 patients. BMJ. 2004;329(7456):15-19.

19. Bordet R, Gautier S, Le Louet H, Dupuis B, Caron J. Analysis of the direct cost of adverse drug reactions in hospitalised patients. Eur J Clin Pharmacol. 2001;56(12):935-941.

20. Carrasco-Garrido P, de Andrés LA, Barrera VH, de Miguel GÁ, Jiménez-García $\mathrm{R}$. Trends of adverse drug reactions related-hospitalizations in Spain (2001-2006). BMC Health Serv Res. 2010;10:287.

21. Kim MH, Lin J, Hussein M, Battleman D. Incidence and economic burden of suspected adverse events and adverse event monitoring during AF therapy. Curr Med Res Opin. 2009;25(12):3037-3047.

22. Yee JL, Hasson NK, Schreiber DH. Drug-related emergency department visits in an elderly veteran population. Ann Pharmacother. 2005;39(12):1990-1995.

23. Lagnaoui R, Moore N, Fach J, Longy-Boursier M, Bégaud B. Adverse drug reactions in a department of systemic diseases-oriented internal medicine: prevalence, incidence, direct costs and avoidability. Eur $J$ Clin Pharmacol. 2000;56(2):181-186.

24. Hafner JW Jr, Belknap SM, Squillante MD, Bucheit KA. Adverse drug events in emergency department patients. Ann Emerg Med. 2002;39(3): 258-267.

25. Bates DW, Spell N, Cullen DJ, et al. The costs of adverse drug events in hospitalized patients. Adverse Drug Events Prevention Study Group. JAMA 1997;277(4):307-311.

26. Rottenkolber D, Schmiedl S, Rottenkolber M, et al: Net of Regional Pharmacovigilance Centers. Adverse drug reactions in Germany: direct costs of internal medicine hospitalizations. Pharmacoepidemiol Drug Saf. 2011;20(6):626-634.

27. Senst BL, Achusim LE, Genest RP, et al. Practical approach to determining costs and frequency of adverse drug events in a health care network. Am J Health Syst Pharm. 2001;58(12):1126-1132.

28. Tafreshi MJ, Melby MJ, Kaback KR, Nord TC. Medication-related visits to the emergency department: a prospective study. Ann Pharmacother. 1999;33(12):1252-1257.

29. Schneeweiss S, Hasford J, Göttler M, Hoffmann A, Riethling AK, Avorn J. Admissions caused by adverse drug events to internal medicine and emergency departments in hospitals: a longitudinal populationbased study. Eur J Clin Pharmacol. 2002;58(4):285-291.

30. Rottenkolber D, Hasford J, Stausberg J. Costs of adverse drug events in German hospitals - a microcosting study. Value Health. 2012; 15(6):868-875.

31. Hug BL, Keohane C, Seger DL, Yoon C, Bates DW. The costs of adverse drug events in community hospitals. Jt Comm J Qual Patient Saf. 2012;38(3):120-126.

32. Schneider PJ, Gift MG, Lee YP, Rothermich EA, Sill BE. Cost of medication-related problems at a university hospital. Am J Health Syst Pharm. 1995;52(21):2415-2418.
33. Suh DC, Woodall BS, Shin SK, Hermes-De Santis ER. Clinical and economic impact of adverse drug reactions in hospitalized patients. Ann Pharmacother. 2000;34(12):1373-1379.

34. Classen DC, Pestotnik SL, Evans RS, Lloyd JF, Burke JP. Adverse drug events in hospitalized patients. Excess length of stay, extra costs, and attributable mortality. JAMA. 1997;277(4):301-306.

35. Giuliani J, Marzola M. The management of skin toxicity during erlotinib in advanced non-small cell lung cancer: how much does it cost? Cutan Ocul Toxicol. 2013;32(3):248-251.

36. Gyllensten H, Hakkarainen KM, Hägg S, Carlsten A, Petzold M, Rehnberg C, Jönsson AK. Economic impact of adverse drug events - a retrospective population-based cohort study of 4970 adults. PLoS One. 2014;9(3):e92061.

37. Borovicka JH, Calahan C, Gandhi M, et al. Economic burden of dermatologic adverse events induced by molecularly targeted cancer agents. Arch Dermatol. 2011;147(12):1403-1409.

38. Noize P, Bénard-Laribière A, Aulois-Griot M, Moore N, MiremontSalamé G, Haramburu F. Cutaneous adverse effects of ketoprofen for topical use: clinical patterns and costs. Am J Clin Dermatol. 2010;11(2): $131-136$.

39. Suh DC, Pahwa R, Mallya U. Treatment patterns and associated costs with Parkinson's disease levodopa induced dyskinesia. J Neurol Sci. 2012;319(1-2):24-31.

40. Gyllensten H, Jönsson AK, Rehnberg C, Carlsten A. How are the costs of drug-related morbidity measured?: A systematic literature review. Drug Saf. 2012;35(3):207-219.

41. Lundkvist J, Jönsson B. Pharmacoeconomics of adverse drug reactions. Fundam Clin Pharmacol. 2004;18(3):275-280.

42. European Medicines Agency. Human Medicines Highlights 2015. Available from: http://www.ema.europa.eu/docs/en_GB/document_library/ Brochure/2016/01/WC500199664.pdf. Accessed February 25, s2016.

43. Food and Drug Administration. New Drugs 2015 Summary. Available from: http://www.fda.gov/downloads/Drugs/Development Approval Process/DrugInnovation/UCM485053.pdf. Accessed February 25, 2016.

44. Foley KA, Wang PF, Barber BL, et al. Clinical and economic impact of infusion reactions in patients with colorectal cancer treated with cetuximab. Ann Oncol. 2010;21(7):1455-1461.

45. Thürmann PA. Methods and systems to detect adverse drug reactions in hospitals. Drug Saf. 2001;24(13):961-968.

46. Dormann H, Muth-Selbach U, Krebs S, et al. Incidence and costs of adverse drug reactions during hospitalisation: computerised monitoring versus stimulated spontaneous reporting. Drug Saf. 2000;22(2):161-168.

47. Macedo AF, Marques FB, Ribeiro CF. Can decisional algorithms replace global introspection in the individual causality assessment of spontaneously reported ADRs? Drug Saf. 2006;29(8):697-702.

48. Lang K, Sussman M, Friedman M, et al. Incidence and costs of treatment-related complications among patients with advanced squamous cell carcinoma of the head and neck. Arch Otolaryngol Head Neck Surg. 2009;135(6):582-588.

49. Paessens BJ, von Schilling C, Berger K, et al. Health resource consumption and costs attributable to chemotherapy-induced toxicity in German routine hospital care in lymphoproliferative disorder and NSCLC patients. Ann Oncol. 2011;22(10):2310-2319.

50. Ray S, Bonthapally V, Holen KD, Gauthier G, Wu EQ, Cloutier M, Guérin A. Economic burden of dermatologic adverse drug reactions in the treatment of colorectal, non-small cell lung, and head and neck cancers with epidermal growth factor receptor inhibitors. J Med Econ. 2013;16(2):221-230. 


\section{Supplementary materials}

Table SI Search strategy - Medline and Cochrane Library (MeSH)

Search Search strategy

I ("Costs and Cost Analysis"[Mesh] OR "Cost of Illness"[Mesh] OR "Drug Costs”[Mesh] OR "Hospital Costs”[Mesh] OR "Health Care Costs"[Mesh] OR “Cost-Benefit Analysis”[Mesh])

$2 \quad$ "Drug-Related Side Effects and Adverse Reactions"[Mesh]

3 \#I AND \#2

$4 \quad \# 3$

Filters: English; 20 years

Abbreviation: $\mathrm{MeSH}$, medical subject headings.

Table S2 Search strategy-Embase (Emtree)

\begin{tabular}{ll}
\hline Search & Search strategy \\
\hline I & "cost of illness"/exp OR “cost”/exp OR "health care costs"/exp OR "cost benefit analysis"/exp OR "hospital cost"/exp \\
2 & "drug induced disease"/exp/mj \\
3 & $\#$ AND \#2 \\
4 & $\# 3$ \\
& Filters: English; 20 years \\
\hline
\end{tabular}




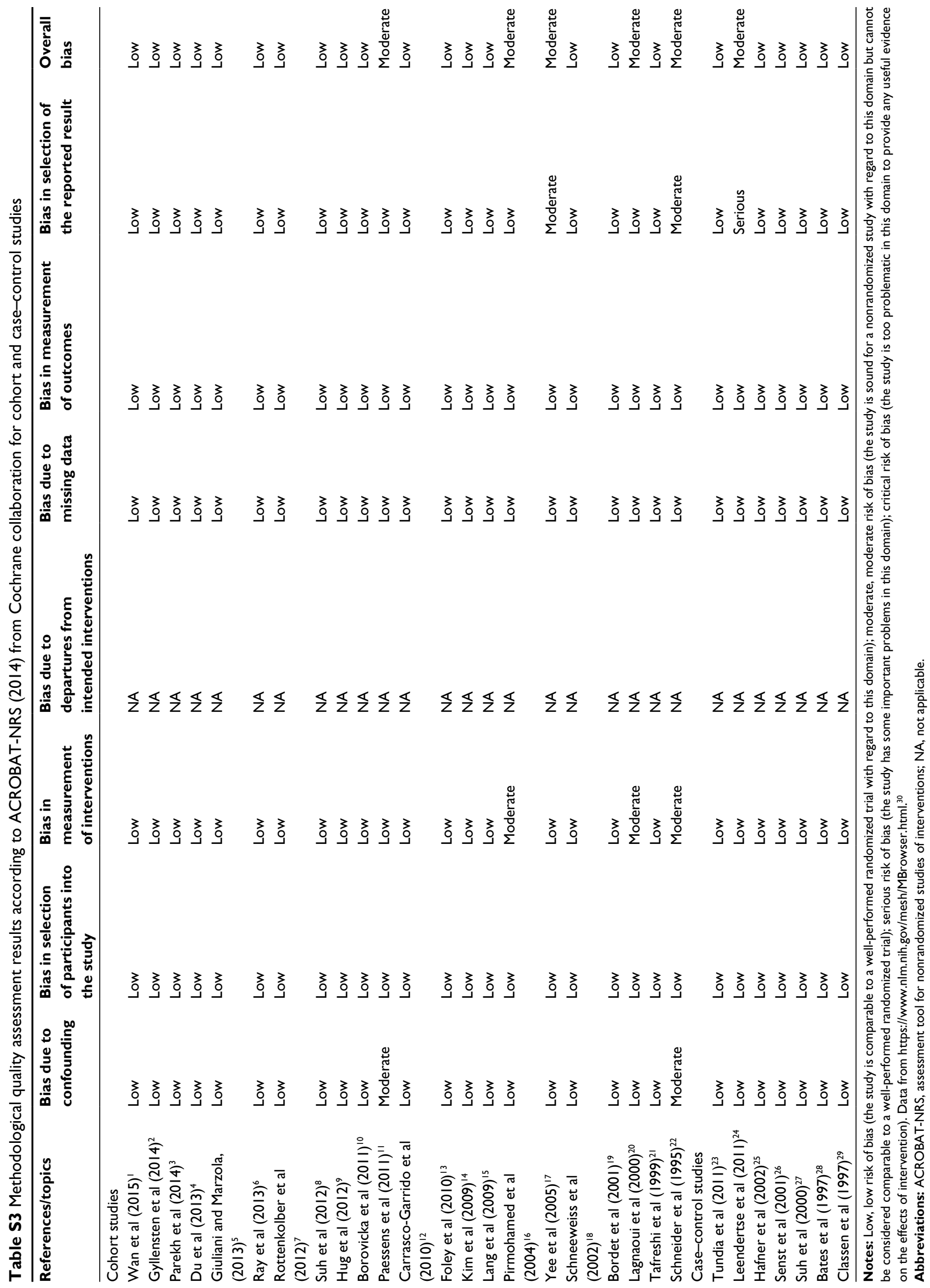




\section{References}

1. Wan Y, Corman S, Gao X, Liu S, Patel H, Mody R. Economic burden of opioid-induced constipation among long-term opioid users with noncancer pain. Am Health Drug Benefits. 2015;8(2):93-102.

2. Gyllensten H, Hakkarainen KM, Hägg S, Carlsten A, Petzold M, Rehnberg C, Jönsson AK. Economic impact of adverse drug events - a retrospective population-based cohort study of 4970 adults. PLoS One. 2014;9(3):e92061.

3. Parekh TM, Raji M, Lin YL, Tan A, Kuo YF, Goodwin JS. Hypoglycemia after antimicrobial drug prescription for older patients using sulfonylureas. JAMA Intern Med. 2014;174(10):1605-1612.

4. Du W, Tutag Lehr V, Caverly M, Kelm L, Reeves J, Lieh-Lai M. Incidence and costs of adverse drug reactions in a tertiary care pediatric intensive care unit. J Clin Pharmacol. 2013;53(5):567-573.

5. Giuliani J, Marzola M. The management of skin toxicity during erlotinib in advanced non-small cell lung cancer: how much does it cost? Cutan Ocul Toxicol. 2013;32(3):248-251.

6. Ray S, Bonthapally V, Holen KD, Gauthier G, Wu EQ, Cloutier M, Guérin A. Economic burden of dermatologic adverse drug reactions in the treatment of colorectal, non-small cell lung, and head and neck cancers with epidermal growth factor receptor inhibitors. J Med Econ. 2013;16(2):221-230.

7. Rottenkolber D, Hasford J, Stausberg J. Costs of adverse drug events in German hospitals - a microcosting study. Value Health. 2012;15(6):868-875.

8. Suh DC, Pahwa R, Mallya U. Treatment patterns and associated costs with Parkinson's disease levodopa induced dyskinesia. J Neurol Sci. 2012;319(1-2):24-31.

9. Hug BL, Keohane C, Seger DL, Yoon C, Bates DW. The costs of adverse drug events in community hospitals. Jt Comm J Qual Patient Saf. 2012;38(3):120-126.

10. Borovicka JH, Calahan C, Gandhi M, et al. Economic burden of dermatologic adverse events induced by molecularly targeted cancer agents. Arch Dermatol. 2011;147(12):1403-1409.

11. Paessens BJ, von Schilling C, Berger K, et al. Health resource consumption and costs attributable to chemotherapy-induced toxicity in German routine hospital care in lymphoproliferative disorder and NSCLC patients. Ann Oncol. 2011;22(10):2310-2319.

12. Carrasco-Garrido P, de Andrés LA, Barrera VH, de Miguel GÁ, Jiménez-García R. Trends of adverse drug reactions related-hospitalizations in Spain (2001-2006). BMC Health Serv Res. 2010;10:287.

13. Foley KA, Wang PF, Barber BL, et al. Clinical and economic impact of infusion reactions in patients with colorectal cancer treated with cetuximab. Ann Oncol. 2010;21(7):1455-1461.

14. Kim MH, Lin J, Hussein M, Battleman D. Incidence and economic burden of suspected adverse events and adverse event monitoring during AF therapy. Curr Med Res Opin. 2009;25(12):3037-3047.

15. Lang K, Sussman M, Friedman M, et al. Incidence and costs of treatment-related complications among patients with advanced squamous cell carcinoma of the head and neck. Arch Otolaryngol Head Neck Surg. 2009;135(6):582-588.
16. Pirmohamed M, James S, Meakin S, et al. Adverse drug reactions as cause of admission to hospital: prospective analysis of 18820 patients. BMJ. 2004;329(7456):15-19.

17. Yee JL, Hasson NK, Schreiber DH. Drug-related emergency department visits in an elderly veteran population. Ann Pharmacother. 2005;39(12):1990-1995.

18. Schneeweiss S, Hasford J, Göttler M, Hoffmann A, Riethling AK, Avorn J. Admissions caused by adverse drug events to internal medicine and emergency departments in hospitals: a longitudinal population-based study. Eur J Clin Pharmacol. 2002;58(4): 285-291.

19. Bordet R, Gautier S, Le Louet H, Dupuis B, Caron J. Analysis of the direct cost of adverse drug reactions in hospitalised patients. Eur J Clin Pharmacol. 2001;56(12):935-941.

20. Lagnaoui R, Moore N, Fach J, Longy-Boursier M, Bégaud B. Adverse drug reactions in a department of systemic diseases-oriented internal medicine: prevalence, incidence, direct costs and avoidability. Eur $J$ Clin Pharmacol. 2000;56(2):181-186.

21. Tafreshi MJ, Melby MJ, Kaback KR, Nord TC. Medication-related visits to the emergency department: a prospective study. Ann Pharmacother. 1999;33(12):1252-1257.

22. Schneider PJ, Gift MG, Lee YP, Rothermich EA, Sill BE. Cost of medication-related problems at a university hospital. Am J Health Syst Pharm. 1995;52(21):2415-2418.

23. Tundia NL, Heaton PC, Kelton CM. The national burden of E-codeidentified adverse drug events among hospitalized children using a national discharge database. Pharmacoepidemiol Drug Saf. 2011;20(8): 866-878.

24. Leendertse AJ, Van Den Bemt PM, Poolman JB, Stoker LJ, Egberts AC, Postma MJ. Preventable hospital admissions related to medication (HARM): cost analysis of the HARM study. Value Health. 2011;14(1):34-40.

25. Hafner JW Jr, Belknap SM, Squillante MD, Bucheit KA. Adverse drug events in emergency department patients. Ann Emerg Med. 2002;39(3):258-267.

26. Senst BL, Achusim LE, Genest RP, et al. Practical approach to determining costs and frequency of adverse drug events in a health care network. Am J Health Syst Pharm. 2001;58(12):1126-1132.

27. Suh DC, Woodall BS, Shin SK, Hermes-De Santis ER. Clinical and economic impact of adverse drug reactions in hospitalized patients. Ann Pharmacother. 2000;34(12):1373-1379.

28. Bates DW, Spell N, Cullen DJ, et al. The costs of adverse drug events in hospitalized patients. Adverse Drug Events Prevention Study Group. JAMA. 1997;277(4):307-311.

29. Classen DC, Pestotnik SL, Evans RS, Lloyd JF, Burke JP. Adverse drug events in hospitalized patients. Excess length of stay, extra costs, and attributable mortality. JAMA. 1997;277(4): 301-306.

30. U.S. National Library of Medicine. Medical Subject Headings. Available from: https://www.nlm.nih.gov/mesh/MBrowser.html. Accessed February 4, 2016.
ClinicoEconomics and Outcomes Research

\section{Publish your work in this journal}

ClinicoEconomics and Outcomes Research is an international, peerreviewed open-access journal focusing on health technology assessment, pharmacoeconomics and outcomes research in the areas of diagnosis, medical devices, and clinical, surgical and pharmacological intervention. The economic impact of health policy and health systems

\section{Dovepress}

organization also constitute important areas of coverage. The manuscript management system is completely online and includes a very quick and fair peer-review system, which is all easy to use. Visit http://www.dovepress.com/testimonials.php to read real quotes from published authors. 